Pediatric/Craniomaxillofacial/Head\&Neck Image

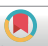

\section{Alopecic and aseptic nodules of the scalp: an underdiagnosed entity}

Kun-Yong Sung ${ }^{1 *}$, Seungkoo Lee ${ }^{2 *}$, Yeonjin Jeong ${ }^{3}$, Sang-Yeul Lee ${ }^{3}$

Departments of ${ }^{1}$ Plastic and Reconstructive Surgery and ${ }^{2}$ Anatomic Pathology, Kangwon National University School of Medicine, Chuncheon; ${ }^{3}$ Department of Plastic and Reconstructive Surgery, Kangwon National University Hospital, Chuncheon, Korea

Correspondence: Sang-Yeul Lee

Department of Plastic and Reconstructive Surgery, Kangwon National University Hospital, 156 Baengnyeong-ro, Chuncheon 24289, Korea

Tel: +82-33-258-9258, Fax: +82-33-258-4920, E-mail: serafin5@unitel.co.kr

*The two authors contributed equally to this work.

Received: July 23, 2020 • Revised: September 6, 2021 •

Accepted: September 30, 2021

pISSN: 2234-6163• elSSN: 2234-6171

https://doi.org/10.5999/aps.2021.01459 • Arch Plast Surg 2022;49:59-60

Copyright (c) 2022 The Korean Society of Plastic and Reconstructive Surgeons This is an Open Access article distributed under the terms of the Creative Commons Attribution Non-Commercial License (https://creativecommons.org/licenses/by-nc/4.0/) which permits unrestricted non-commercial use, distribution, and reproduction in any medium, provided the original work is properly cited.

Alopecic and aseptic nodules of the scalp (AANS) is an underdiagnosed entity characterized by one or more dome-shaped alopecic nodule(s) that predominantly affects young men. The singular aspect of the nodules, nonscarring alopecia, deep inflammatory infiltrate, and efficacy of doxycycline confer specificity to AANS [1]. The etiology remains unclear, but AANS might be included in a spectrum of diseases such as dissecting cellulitis of the scalp, acne conglobate, and hidradenitis suppurativa, which share the common pathogenesis: follicular occlusion, follicular rupture, then follicular infection. AANS is diagnosed based on clinicohistopathological features. The preferred treatment is doxycycline. Other options include aspiration or puncture, intralesional corticosteroid injection, and surgical excision. The prognosis is usually good, and alopecia is reversible either spontaneously or after treatment especially with doxycycline [1]. Herein, we report a case of AANS to facilitate its recognition and proper management. A 22-year-old man presented with an asymptomatic scalp mass lasting 3 weeks (Fig. 1A). Physical examination revealed a dome-shaped, tender, fluctuating, and alopecic nodule in the
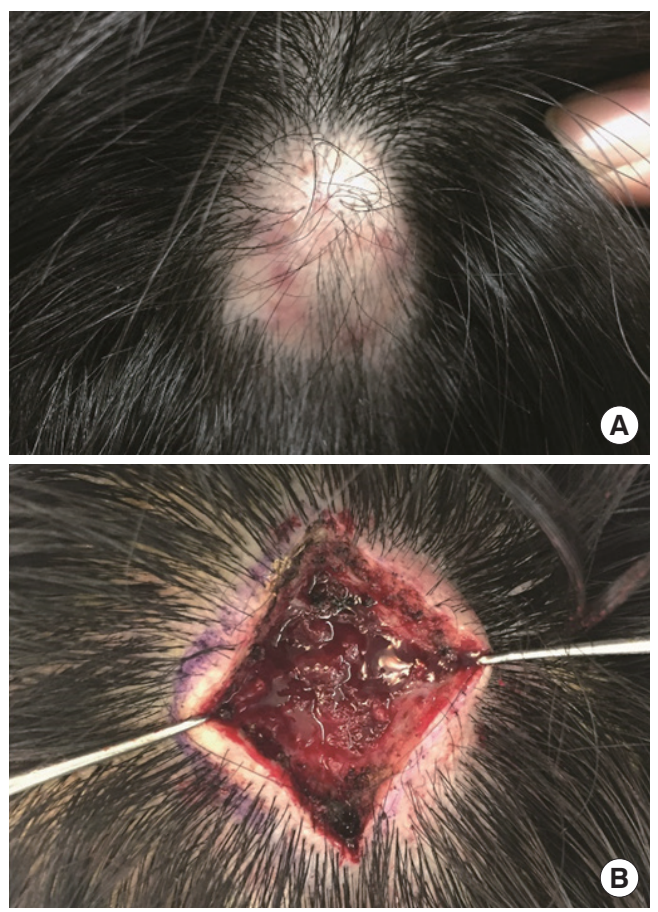

Fig. 1.

Clinical features of the patient. (A) Preoperative photograph showing a $2.5-\mathrm{cm}$ diameter, dome-shaped alopecic nodule in the occipital region.

(B) Intraoperative photograph showing the lesion filled with granulation tissue.
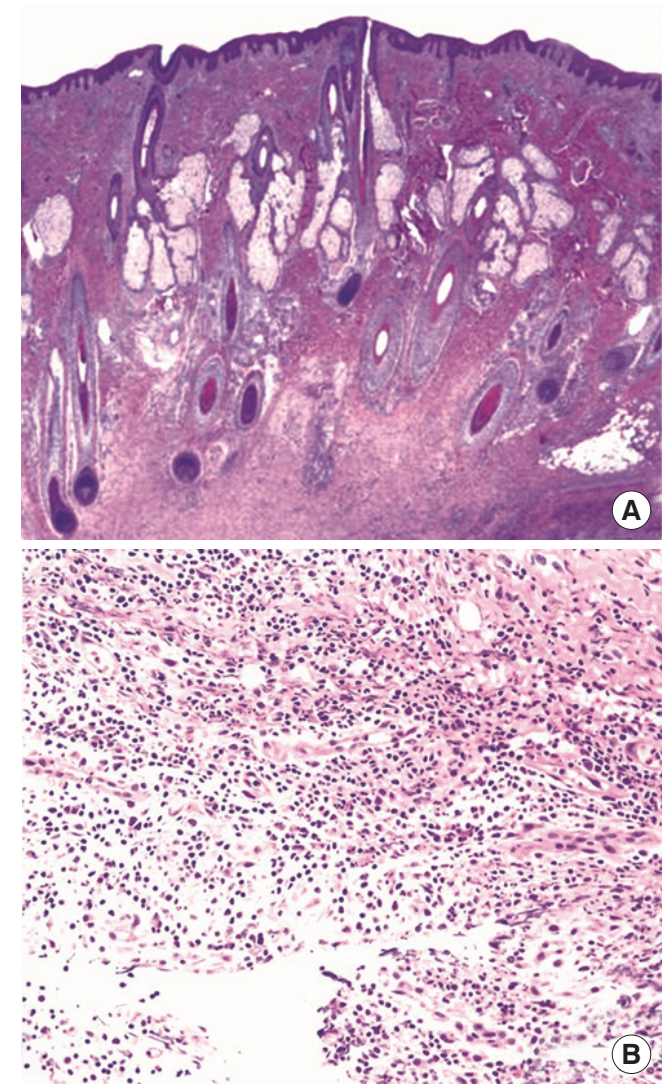

Fig. 2.

Microscopic examination. (A) Inflammatory lesion in the deep dermis $(H \& E, \times 15)$. (B) Inflammatory lesion showing mixed chronic and acute inflammatory cells, such as lymphocytes, plasma cells, neutrophils, and histiocytes (H\&E, $\times 40)$. occipital region. The puncture was negative.

Intraoperatively, the lesion was filled with chronic granulation tissue (Fig. 1B). After surgical removal of the lesion, the involved scalp was minimally excised and closed. Histopathologic examination showed a 
chronic inflammatory lesion along with mixed inflammatory cells in the deep dermis (Fig. 2). The postoperative course was uneventful over 6 months postoperatively and the hair growth in the area previously affected by the lesion was restored. Considering that only a portion of the alopecic area was excised during the excisional biopsy, we believe that alopecia was recovered spontaneously following the natural courses of the lesion. This underdiagnosed entity requires careful clinical consideration to make an accurate diagnosis and adequately manage patients. AANS should be differentiated from other scalp lesions such as inflamed trichilemmal cysts, alopecia areata, bacterial folliculitis, dissecting cellulitis of the scalp, and metastatic nodules [2].

\section{Notes}

\section{Conflict of interest}

No potential conflict of interest relevant to this article was reported.

\section{Ethical approval}

The study was approved by the Institutional Review Board of Kangwon National University Hospital (IRB No. KNUH-2021-07-007). Written informed consent was obtained.

\section{Patient consent}

The patient provided written informed consent for the publication and the use of his images.

\section{Author contribution}

Conceptualization: SY Lee. Writing - original draft:

KY Sung. Writing - review \& editing: S Lee, SY Lee. Methodology: Y Jeong. Visualization: S Lee.

Approval of final manuscript: all authors.

\section{ORCID}

Kun-Yong Sung

https://orcid.org/0000-0002-3114-0001

Seungkoo Lee

https://orcid.org/0000-0003-1317-4133

Yeonjin Jeong

https://orcid.org/0000-0003-0062-8546

Sang-Yeul Lee

https://orcid.org/0000-0001-5262-1499

\section{References}

1. Abdennader S, Vignon-Pennamen MD, Hatchuel J, et al. Alopecic and aseptic nodules of the scalp (pseudocyst of the scalp): a prospective clinicopathological study of 15 cases. Dermatology 2011;222:31-5.

2. Fischer-Levancini C, Gompertz M, Guglielmetti A, et al. Alopecic and aseptic nodules of the scalp: first report in South America and second in America. Skin Appendage Disord 2018;4:78-81. 